\title{
Long-term Outcomes in Adolescents and Adults with a Cleft Lip and/or palate: Esthetics, Employment and Functioning
}

\section{Cassandra Alighieri ( $\square$ cassandra.alighieri@ugent.be)}

Ghent University https://orcid.org/0000-0001-7593-8595

\section{Evelien D'haeseleer}

Ghent University: Universiteit Gent

\section{Kim Bettens}

Ghent University: Universiteit Gent

\section{Katrien Bonte}

University Hospital Ghent: Universitair Ziekenhuis Gent

Hubert Vermeersch

University Hospital Ghent: Universitair Ziekenhuis Gent

Nele Vermeire

Ghent University: Universiteit Gent

\section{Merel Claeys}

Ghent University: Universiteit Gent

\section{Daniel Sseremba}

CoRSU Hospital Uganda

George Galiwango

CoRSU hospital Uganda

\section{Kristiane Van Lierde}

Universiteit Gent

\section{Research}

Keywords: Cleft lip and palate, long-term outcomes, employment, functioning

Posted Date: February 5th, 2021

DOI: https://doi.org/10.21203/rs.3.rs-166715/v1

License: (c) (1) This work is licensed under a Creative Commons Attribution 4.0 International License. Read Full License 


\section{Abstract}

Background. To date, there seems to be no consensus on the long-term quality of life outcomes in patients living with a cleft of the lip and/or palate (CL/P) with regard to well-being and functioning. Some studies report a substantial influence of having a cleft while other studies report no influence of living with a cleft. The purpose of this study was to investigate the impact of living with a CL/P on esthetics, employment and functioning in Dutchspeaking adolescents and adults with a CL/P.

Methods. 30 Patients with a CL/P (19 men and 11 women) were included in the study. The mean age of the participants was 26.93 years $(S D=11.688$ years, range $=15-66$ years $)$. An age and gender matched control group was included consisting of 30 participants (19 men and 11 women) without a CL/P with a mean age of 26.87 years $(S D=11.729$ years, range $=16-67$ years $)$. Esthetics, employment and functioning were assessed using different standardized self-report questionnaires.

Results. No statistically significant difference in educational level, employment, monthly net income, marital status and having children was found between participants with and without a CL/P. In addition, the quality of life scores did not differ between the two groups. Within the group of individuals with a CL/P, the findings revealed that the proportion of participants who reported an influence of the CL/P on daily functioning, general well-being, social contacts, family life, applying for a job, work, education and leisure time differed by age. Older individuals experienced more influence of their CL/P compared to younger individuals. With regard to esthetics, the findings revealed that participants without a CL/P were less satisfied with the appearance of their jaws compared to participants with a CL/P.

Conclusion. In general, the findings of our study revealed no significant differences between adolescents and adults with and without a CL/P with regard to employment and functioning. Considering age within the group of participants with a $\mathrm{CL} / \mathrm{P}$, however, the results demonstrated that older individuals were more likely to experience a negative impact of their cleft on well-being and functioning. These findings suggest that older individuals with a CL/P might benefit from additional socio-emotional support, for example peer contacts and support groups or psychological guidance. Longitudinal research on this topic is highly needed to determine possible fluctuations in the impact of living with a CL/P.

\section{Introduction}

A cleft of the lip with or without a cleft of the palate (CL/P) is considered a condition with lifelong consequences [1]. Long-term outcomes have been described extensively with regard to esthetics, orthodontics and other medical outcomes [2-4]. Facial esthetics have been known to have a major impact on an adolescent's or adult's general perception of life [5]. A study in adult patients with a CL/P revealed that individuals with a CL/P rated their esthetic outcomes significantly worse than experts [5]. Especially female patients were dissatisfied with their appearance [5]. In accordance, it has been reported that females were more vulnerable to the stigmata related to a CL/P compared with males $[4,6]$. Facial appearance plays a major role in the development of interpersonal relationships with individuals from the same or the other sex [7]. A study performed in 24 adolescents with a CL/P (age range: 11 to 13 years) revealed that dissatisfaction with facial appearance was associated with issues to establish peer relationships and with loneliness [8]. During adolescence, the establishment of friendships and relationships with peers can be particularly challenging because individuals with a CL/P are often teased during this period of life [9]. In general, these studies mostly focused on the consequences and the impact of a deviant appearance. The 
influence of a CL/P on functioning and well-being during adolescence and adulthood, however, has received less attention.

A study performed by Oosterkamp, Dijkstra [10] investigated the influence of having a cleft on social functioning and well-being in patients with a bilateral cleft of the lip and palate (BCLP). Forty-three adults with a BCLP were included in the study. The findings revealed that about $20 \%$ of the patients experienced a substantial influence of their cleft on general well-being, attending education and spending leisure time. Interestingly, only $5 \%$ of the participants experienced a substantial influence of having a BCLP on family life. The authors suggested that patients with BCLP tend to have a close contact with their parents. In addition, they tend to rely heavily on their families for social activities. Following education, applying for a job and spending leisure time are novel and unknown situations in which individuals are forced to leave the protected family environment and are confronted with people looking at them and asking questions. It was suggested that patients with BCLP are more anxious about social acceptance because of concerns about facial appearance. The authors hypothesized that the patients' appraisal of unfamiliar people and situations was therefore more likely to be negative. These findings suggest that there is a significant influence of a cleft on well-being and social functioning. Unfortunately, this study only included adults with BCLP. Adults with a cleft of the lip (CL), a cleft of the palate (CP), or a cleft of the lip and palate (CLP) might also experience these issues. To date, few studies investigated long-term outcomes among patients with different cleft types.

A qualitative study performed by Stock, Feragen [1] responded to this need by exploring the psychological adjustment and possible support needs of 52 adults born with CL, CP or CLP using individual telephone interviews. The interviews revealed that most participants were socially well-adjusted and involved in long-term romantic relationships which was in contrast with quantitative studies. Some of the interviews alluded to a raised level of social anxiety in certain situations. Some participants with CL, CP or CLP had developed strategies to cope with this, such as withdrawal or being overly "loud" or "pushy" to compensate for their discomfort. A lack of selfconfidence in some participants resulted in struggles to form romantic relationships. About half of the participants in this study $(24 / 52,46.2 \%)$ had children of their own. Some participants reported that they had consciously chosen to not have children because of the recurrence risk of CL/P. Despite that most studies on educational attainment of individuals with CL/P suggested that patients born with a cleft are likely to be educationally disadvantaged [10-12], results of this qualitative study found that most patients had achieved a high educational level and were employed in a wide range of settings. Another qualitative study conducted in 6 adults with a CL/P revealed that the cleft had an ongoing impact on their lives, although the focus of this impact shifted over time (Hamlet \& Harcourt, 2015). The findings of this study revealed that specifically for adults between the ages of 57 and 82 years, a CL/P influenced romantic relationships and the decision to have children of their own. These qualitative studies, however, were unable to gauge any effect of age or gender on well-being and functioning. The authors argued that further research is necessary to investigate the influence of these potential variables.

In summary, there seems to be no consensus on the long-term outcomes in patients with a CL/P with regard to well-being and functioning with some studies reporting a substantial influence of having a cleft and other studies reporting no influence of having a cleft. The purpose of this study was to investigate the impact of living with a $\mathrm{CL} / \mathrm{P}$ on esthetics, employment and functioning in Dutch-speaking adolescents and adults with a CL/P living in Flanders (i.e., the Northern part of Belgium). The possible impact of the CL/P was measured using self-report questionnaires. The results on these questionnaires were compared with the results of an age and gender matched control group consisting of adolescents and adults without a CL/P. Within the group of participants with a CL/P, 
we investigated the possible effects of age and gender. Based on previous literature, we hypothesized that the presence of a CL/P would still have a substantial influence on well-being and functioning in older participants [13]. In addition, it was hypothesized that females living with a CL/P would experience a higher impact of their cleft compared to males living with a $\mathrm{CL} / \mathrm{P}[4,6]$.

\section{Methods}

This study was approved by the Ethics Committee of the (blinded for review) University Hospital. Every individual participated voluntarily and signed an informed consent.

\subsection{Participants}

Dutch-speaking individuals living in Flanders (i.e., the Northern part of Belgium) who were older than 16 years and who were born with an isolated repaired CL/P could participate in the present study. These adolescents and adults were recruited from the speech-language consultations at (blinded for review) University Hospital using purposive sampling. Individuals were excluded if: (1) Dutch was not their mother tongue, or if (2) they had syndromes or any cognitive or related learning disabilities or neuromotor disabilities. Based on these criteria, 48 possible participants were selected. The questionnaires were sent by post to the participant's residence.

An age and gender matched control group of individuals without a CL/P was recruited from the investigators' environment using convenience and snowball sampling. Similar to the procedure for the participants with a CL/P, the participants received the questionnaires by post.

\subsection{Questionnaires}

\subsubsection{Influence of $\mathrm{CL} / \mathrm{P}$ on education, employment and marital status}

The participants were asked some demographic questions related to (1) educational level (i.e., primary education, secondary education, bachelor degree, master degree), (2) employment (i.e., worker, employee, independent profession, no job, retirement, student), (3) monthly net income (i.e., <€1,000, €1,001 - €1,500, €1,501 - €2,000, $€ 2,001-€ 2,5000$ or $>€ 3,000$ ), (4) marital status (i.e., single, in a relationship, married, widow, or divorced) and (5) having children (i.e., yes or no).

\subsubsection{Generic quality of life questionnaire}

Participants were administered the Dutch translation of the standardized RAND-36 questionnaire [14, 15]. RAND-36 is a multidimensional generic quality of life questionnaire which assesses 8 different health domains: (1) physical functioning, (2) social functioning, (3) physical role impairment, (4) emotional role impairment, (5) mental health, (6) vitality, (7) pain, and (8) general health experience. Depending on the domain, the respondent is asked to rate different statements on 3-6 point Likert scales. The participants' scores on the several domains were transformed to a scale ranging from 0 to 100 with a higher score reflecting a better health condition.

\subsubsection{Satisfaction with appearance and functioning}

The participants' satisfaction with appearance and functioning was assessed using a Visual Analogue Scale (VASscale) asking them to place a mark on a $100 \mathrm{~mm}$ bar. Concerning the participants' satisfaction with appearance, 
they were asked to rate their satisfaction with the appearance of their (1) upper lip, (2) nose, (3) teeth, (4) jaws, and (5) face. The participants' satisfaction with functioning was assessed in terms of (1) speech, (2) speech intelligibility, (3) hearing, (4) breathing through the nose, and (5) drinking. For each parameter, a bar was provided including the label "not satisfied at all" $(0 \mathrm{~mm})$ at the left end and the label "completely satisfied" (100 mm) at the right end.

\subsubsection{The Satisfaction with Life Scale}

The Dutch version of the Satisfaction With Life Scale (SWLS) was used to assess satisfaction with the respondent's life as a whole [16-18]. Participants are asked to indicate how much they agree or disagree with each of the 5 items using a 7-point scale that ranges from 1 (strongly disagree) to 7 (strongly agree). Scores can range from 5 to 35, with a score of 20 representing a neutral point on the scale. Scores between 5 and 9 indicate that the respondent is extremely dissatisfied with life whereas scores between 31 and 35 indicate that the respondent is extremely satisfied with life.

\subsubsection{Social Avoidance and Distress Scale}

The Social Avoidance and Distress Scale (SADS) assesses social anxiety and avoidance behavior using 28 different statements [19]. The participant is asked to assess whether the statements are true (score 1) or false (score 0 ) to them. The scores on the different items are summed resulting in a SADS total score. The total score is divided into three separate categories: (1) low scores (i.e., 0 or 1), (2) average scores (i.e., 2 to 11) and (3) high scores (i.e., $\geq 12$ ). High scores connote high social anxiety and distress.

\subsubsection{Influence of $\mathrm{CL/P}$ on well-being and functioning}

Adults with a CL/P were asked to rate the influence of having a cleft on eight different dimensions: (1) daily functioning, (2) general well-being, (3) social contacts, (4) family life, (5) applying for a job, (6) work, (7) education, and (8) leisure time on a 5-point Likert scale ranging from 1 (no influence of the cleft) to 5 (a large influence of the cleft) [10]. In accordance with Oosterkamp, Dijkstra [10], the scores on the Likert scale were dichotomized into "no influence or a little influence of the cleft" (scores 1-2) and "a substantial influence of the cleft" (scores 3-5).

\subsection{Statistical analysis}

Statistical analysis was performed using SPSS version 24.0 (SPSS Inc., Chicago, IL, USA). Analyses were conducted at $a=.05$. For all continuous variables, normality was tested based on the descriptive statistics that were generated for all collected data (histogram, boxplot, Q-Q plot) and the results of the Shapiro-Wilk test.

Because the continuous variables were non-parametrically distributed, the Mann-Whitney $U$ test was used to compare these variables between participants with and without a CL/P. P-values for the Mann-Whitney U test were adjusted using Bonferroni correction at $p<0.025(0.05 / 2)$. To compare categorical variables, the Pearson $\chi^{2}$ test was used.

\section{Results}

\subsection{Participants}

The questionnaires were returned by 30 individuals with a CL/P (response rate: $30 / 48,62.5 \%$ ). Thereby, 30 patients with a CL/P (19 men and 11 women) were included in the study. The mean age of the participants was 26.93 
years $(S D=11.688$ years, range $=15-66$ years). Fifteen participants $(15 / 30,50 \%)$ had a cleft of the lip and palate. Six participants $(6 / 30,20 \%)$ had a cleft of the lip and three participants had a cleft of the palate $(3 / 30,10 \%)$. Mean age of lip closure was 3 months ( $S D=1$ month), mean age of palatal closure was 13 months ( $S D=2$ months). Lip closure was performed using a modified Millard technique or the procedure described by Tennison [20, 21]. Clefts of the palate were repaired using Sommerlad primary palatoplasty [22]. Surgical details for the group of participants with a CL/P are presented in Table 1.

Table 1

Surgical details for the group of participants with a $\mathrm{CL} / \mathrm{P}(n=30)$

\begin{tabular}{|ll|}
\hline & Participants with a CL/P $(\boldsymbol{n}=\mathbf{3 0})$ \\
\hline Lip closure (mean age, $S D)$ & 3 months (SD=1 month) \\
\hline Palatal closure (mean age, $S D)$ & 12 months (SD=2 months) \\
\hline Presence of oronasal fistula ${ }^{1}$ & $n=3,10.0 \%$ \\
\hline Secondary surgery & $\begin{array}{l}\text { Secondary lip repair }(n=1,3.3 \%) \\
\text { Sphincter pharyngoplasty }(n=2,6.7 \%)\end{array}$ \\
\hline Additional surgeries & $n=2,6.7 \%$ \\
\hline Le Fort I osteotomy & $n=9,30.0 \%$ \\
\hline Rhinoplasty & $n=5,20.0 \%$ \\
\hline Lipofilling of the upper lip & \\
\hline Presence or absence of oronasal fistula was assessed at the moment of filling in the questionnaire \\
\hline
\end{tabular}

The control group included 30 participants (19 men and 11 women) without a CL/P with a mean age of 26.87 years $(S D=11.729$ years, range $=16-67$ years). No statistically significant differences in age $(U=448.500, p=.982$ ) nor in gender $\left(\chi^{2}(23)=11.210, p=1.000\right)$ were found between the two groups.

\subsection{Influence of CL/P on education, employment and marital status}

The responses of the participants with and without a CL/P are presented in Table 2. In general, the Pearson $\chi 2$ test demonstrated that there were no significant differences between participants with and without a CL/P in terms of educational level, employment, monthly net income, marital status and having children. 
Table 2

Results of the Pearson $\chi 2$ test comparing participants with and without CL/P in terms of educational level, employment, monthly net income, marital status and having children.

\begin{tabular}{|c|c|c|c|c|c|}
\hline & & $\begin{array}{l}\text { Participants with a } \\
\text { CL/P } \\
(n=30)\end{array}$ & $\begin{array}{l}\text { Participants without a CL/P } \\
(n=30)\end{array}$ & $\chi^{2}(d f)$ & $\begin{array}{l}p- \\
\text { value }\end{array}$ \\
\hline \multirow[t]{4}{*}{$\begin{array}{l}\text { Educational } \\
\text { level }\end{array}$} & $\begin{array}{l}\text { Primary } \\
\text { education }\end{array}$ & $6 / 30(20.0 \%)$ & $1 / 30(3.3 \%)$ & \multirow[t]{4}{*}{$\begin{array}{l}10.822 \\
(9)\end{array}$} & \multirow[t]{4}{*}{.275} \\
\hline & $\begin{array}{l}\text { Secondary } \\
\text { education }\end{array}$ & $18 / 30(60 \%)$ & $18 / 30(60.0 \%)$ & & \\
\hline & Bachelor degree & $5 / 30(16.7 \%)$ & $9 / 30(30.0 \%)$ & & \\
\hline & Master degree & 1/30 (3.3\%) & $2 / 30(6.7 \%)$ & & \\
\hline \multirow[t]{6}{*}{ Employment } & Worker & $7 / 30(23.3 \%)$ & 4/30 (13.3\%) & \multirow{6}{*}{$\begin{array}{l}5.358 \\
(8)\end{array}$} & \multirow[t]{6}{*}{.823} \\
\hline & Employee & $2 / 30(6.7 \%)$ & $5 / 30(16.7 \%)$ & & \\
\hline & $\begin{array}{l}\text { Independent } \\
\text { profession }\end{array}$ & $0 / 30(0.0 \%)$ & 1/30 (3.3\%) & & \\
\hline & No job & $6 / 30(20.0 \%)$ & $5 / 30(16.7 \%)$ & & \\
\hline & Retirement & 1/30 (3.3\%) & 1/30 (3.3\%) & & \\
\hline & Student & 13/30 (43.3\%) & $12 / 30(40.0 \%)$ & & \\
\hline \multirow{5}{*}{$\begin{array}{l}\text { Monthly net } \\
\text { income }\end{array}$} & $<€ 1,000$ & 1/13 (7.7\%) & $1 / 15(6.6 \%)$ & \multirow{5}{*}{$\begin{array}{l}2.293 \\
(4)\end{array}$} & \multirow[t]{5}{*}{.834} \\
\hline & $€ 1,001-€ 1,500$ & $6 / 13(46.2 \%)$ & 5/15 (33.3\%) & & \\
\hline & $€ 1,501-€ 2,000$ & $5 / 13(38.5 \%)$ & 5/15 (33.3\%) & & \\
\hline & $€ 2,001-€ 2,5000$ & 1/13 (7.7\%) & $2 / 15(13.3 \%)$ & & \\
\hline & $>€ 3,000$ & $0 / 13(0.0 \%)$ & $2 / 15(13.3 \%)$ & & \\
\hline \multirow[t]{4}{*}{ Marital status } & Single & 10/30 (33.3\%) & $7 / 30$ (23.3\%) & \multirow{4}{*}{$\begin{array}{l}9.602 \\
(5)\end{array}$} & \multirow[t]{4}{*}{.074} \\
\hline & In a relationship & 11/30 (36.7\%) & $11 / 30(36.7 \%)$ & & \\
\hline & Married & $3 / 30(\%)$ & $8 / 30(26.7 \%)$ & & \\
\hline & Divorced & $2 / 30(6.7 \%)$ & $3 / 30(10.0 \%)$ & & \\
\hline \multirow[t]{2}{*}{ Children } & No & $24 / 30(80.0 \%)$ & $23 / 30(76.7 \%)$ & \multirow{2}{*}{$\begin{array}{l}.098 \\
(1)\end{array}$} & \multirow[t]{2}{*}{1.000} \\
\hline & Yes & 6/30 (20.0\%) & $7 / 30$ (23.3\%) & & \\
\hline
\end{tabular}

\subsection{Generic quality of life questionnaire}

The results for the RAND-36 questionnaire are presented in Table 3. The Mann Whitney U-test demonstrated no statistically significant differences in median scores on the RAND-36 questionnaire between participants with and without a CL/P indicating no differences in generic health condition between these two groups. 
Table 3

Results of the Mann-Whitney U test for the comparison between the responses of the participants with and without $\mathrm{CL} / \mathrm{P}$ on the RAND-36 questionnaire

\begin{tabular}{|c|c|c|c|c|}
\hline \multirow[t]{2}{*}{ RAND-36 domain } & $\begin{array}{l}\text { Participants with a CL/P ( } n \\
=30 \text { ) }\end{array}$ & $\begin{array}{l}\text { Participants without a CL/P ( } n \\
=30 \text { ) }\end{array}$ & \multirow[t]{2}{*}{$\begin{array}{l}U \\
\text { statistic }\end{array}$} & \multirow[t]{2}{*}{$\begin{array}{l}p- \\
\text { value }\end{array}$} \\
\hline & Median (min-max) & Median (min-max) & & \\
\hline Physical functioning & $100.0(35.0-100.0)$ & $100.0(50.0-100.0)$ & 385.5 & .286 \\
\hline Social functioning & $100.0(50.0-100.0)$ & $100.0(38.0-100.0)$ & 455.5 & .928 \\
\hline $\begin{array}{l}\text { Physical role } \\
\text { impairment }\end{array}$ & $100.0(25.0-100.0)$ & $100.0(0.0-100.0)$ & 395.5 & .173 \\
\hline $\begin{array}{l}\text { Emotional role } \\
\text { impairment }\end{array}$ & $100.0(0.0-100.0)$ & $100.0(0.0-100.0)$ & 417.0 & .452 \\
\hline Mental health & $78.0(48.0-100.0)$ & $80.0(40.0-100.0)$ & 425.5 & .715 \\
\hline Vitality & $80.0(35.0-100.0)$ & $80.0(25.0-90.0)$ & 427.0 & .732 \\
\hline Pain & $100.0(57.0-100.0)$ & $89.80(57.0-100.0)$ & 490.0 & .519 \\
\hline $\begin{array}{l}\text { General health } \\
\text { experience }\end{array}$ & $80.0(15.0-100.0)$ & $75.0(35.0-90.0)$ & 553.0 & .126 \\
\hline
\end{tabular}

\subsection{Satisfaction with appearance and functioning}

The median VAS-scores for appearance and functioning are presented in Table 4. The Mann-Whitney U test revealed a statistically significant difference in median VAS-scores for the parameter "satisfaction with appearance of the jaws". Participants without a CL/P were less satisfied with the appearance of their jaws (median VAS score $=8.0$, min-max $=5.0-10.0$ ) compared to participants with a CL/P (median VAS score $=9.0$, min$\max =6.0-10.0)$. For the other VAS-scales regarding appearance and functioning, the Mann-Whitney U test demonstrated no statistically significant differences between participants with and without a CL/P. 
Table 4

Results of the Mann-Whitney U test for the comparison between the responses of the participants with and without $\mathrm{CL} / \mathrm{P}$ on the VAS-scales regarding appearance and functioning

\begin{tabular}{|c|c|c|c|c|}
\hline \multirow[t]{2}{*}{ Satisfaction with } & $\begin{array}{l}\text { Participants with a CL/P ( } n \\
=30 \text { ) }\end{array}$ & $\begin{array}{l}\text { Participants without a CL/P ( } n \\
=30)\end{array}$ & \multirow[t]{2}{*}{$\begin{array}{l}U \\
\text { statistic }\end{array}$} & \multirow[t]{2}{*}{$\begin{array}{l}p- \\
\text { value }\end{array}$} \\
\hline & $\begin{array}{l}\text { VAS median (min-max) } \\
(\mathrm{mm})\end{array}$ & VAS median (min-max) (mm) & & \\
\hline $\begin{array}{l}\text { appearance of the } \\
\text { upper lip }\end{array}$ & $7.0(1.9-10.0)$ & $8.0(4.0-10.0)$ & 331.5 & .076 \\
\hline appearance of the nose & $7.0(0.2-10.0)$ & $7.0(3.0-9.0)$ & 407.5 & .524 \\
\hline $\begin{array}{l}\text { appearance of the } \\
\text { teeth }\end{array}$ & $8.0(1.5-10.0)$ & $7.0(3.0-10.0)$ & 477.5 & .681 \\
\hline appearance of the jaws & $9.0(6.0-10.0)$ & $8.0(5.0-10.0)$ & 607.5 & $.017 *$ \\
\hline appearance of the face & $7.0(3.7-10.0)$ & $8.0(5.0-9.0)$ & 460.0 & .880 \\
\hline appearance (total) & $7.0(4.0-10.0)$ & $7.0(5.4-9.0)$ & 399.5 & .905 \\
\hline speech & $7.5(1.0-10.0)$ & $8.0(5.0-10.0)$ & 422.0 & .893 \\
\hline speech intelligibility & $7.0(2.0-10.0)$ & $8.0(4.0-10.0)$ & 459.0 & .070 \\
\hline hearing & $8.0(2.0-10.0)$ & $7.0(4.0-10.0)$ & 570.5 & .065 \\
\hline $\begin{array}{l}\text { breathing through the } \\
\text { nose }\end{array}$ & $6.0(0.0-10.0)$ & $8.0(4.0-10.0)$ & 326.5 & .385 \\
\hline drinking & $9.6(3.2-10.0)$ & $9.0(6.0-10.0)$ & 506.5 & .455 \\
\hline functioning (total) & $7.4(3.6-10.0)$ & $7.9(5.8-9.2)$ & 407.0 & .524 \\
\hline
\end{tabular}

\subsection{The Satisfaction with Life Scale}

The results for the Satisfaction with Life Scale (SWLS) are presented in Table 5. The Mann-Whitney U test revealed no statistically significant differences in total SWLS scores between participants with and without a CL/P $(U=$ 471.0, $p=.755)$. In accordance, no statistically significant differences for any of the SWLS subscales were observed between the two groups (Table 4). 
Table 5

Results of the Mann-Whitney U test for the comparison between the responses of the participants with and without a CL/P on the Satisfaction With Life Scale (SWLS)

\begin{tabular}{|c|c|c|c|c|}
\hline \multirow[t]{2}{*}{ SWLS } & $\begin{array}{l}\text { Participants with a } \\
\mathrm{CL} / \mathrm{P}(n=30)\end{array}$ & $\begin{array}{l}\text { Participants without } \\
\text { a CL/P }(n=30)\end{array}$ & \multirow[t]{2}{*}{$\begin{array}{l}\text { U } \\
\text { statistic }\end{array}$} & \multirow[t]{2}{*}{$\begin{array}{l}p- \\
\text { value }\end{array}$} \\
\hline & median (min-max) & median (min-max) & & \\
\hline $\begin{array}{l}\text { Item } 1 \text {. For most things, my life is close to } \\
\text { my ideal }\end{array}$ & $6.0(1.0-7.0)$ & $5.0(2.0-7.0)$ & 492.5 & .515 \\
\hline $\begin{array}{l}\text { Item 2. The conditions of my life are } \\
\text { excellent }\end{array}$ & $6.0(2.0-7.0)$ & $6.0(3.0-7.0)$ & 454.0 & .947 \\
\hline Item 3. I am satisfied with my life & $6.0(1.0-7.0)$ & $6.0(3.0-7.0)$ & 491.0 & .514 \\
\hline $\begin{array}{l}\text { Item } 4 \text {. So far, I have gotten the things that } \\
\text { are important to me in my life }\end{array}$ & $5.0(2.0-7.0)$ & $5.0(1.0-7.0)$ & 478.5 & .666 \\
\hline $\begin{array}{l}\text { Item } 5 \text {. If I were born again, I would change } \\
\text { almost nothing in my life }\end{array}$ & $5.0(1.0-7.0)$ & $5.0(1.0-7.0)$ & 436.0 & .833 \\
\hline Total score SWLS & $26.5(8.0-35.0)$ & $27.0(12.0-35.0)$ & 471.0 & .755 \\
\hline
\end{tabular}

\subsection{Social Avoidance and Distress Scale}

The results for the Social Avoidance and Distress Scale (SADS) per group are presented in Table 6. The Pearson $\chi 2$ test demonstrated that participants with a CL/P did not experience significantly more social anxiety or did not show more avoidance behavior compared to participants without a $\mathrm{CL} / \mathrm{P}\left(\mathrm{X}^{2}(2)=1.061, p=.665\right)$.

Table 6

Results for the Social Avoidance and Distress Scale (SADS) based on the Pearson $\times 2$ test

\begin{tabular}{|c|c|c|c|c|}
\hline \multirow[t]{2}{*}{ SADS categories } & $\begin{array}{l}\text { Participants with a CL/P ( } n= \\
\text { 30) }\end{array}$ & $\begin{array}{l}\text { Participants without a CL/P ( } n= \\
30)\end{array}$ & \multirow[t]{2}{*}{$\chi^{2}(d f)$} & \multirow[t]{2}{*}{$\begin{array}{l}p- \\
\text { value }\end{array}$} \\
\hline & Median (min-max) & Median (min-max) & & \\
\hline Low score (0 or 1$)$ & $4 / 30(13.3 \%)$ & 10/30 (33.3\%) & \multirow{3}{*}{$\begin{array}{l}1.061 \\
(2)\end{array}$} & \multirow[t]{3}{*}{.665} \\
\hline $\begin{array}{l}\text { Average score (2- } \\
\text { 11) }\end{array}$ & $20 / 30(66.7 \%)$ & 17/30 (56.7\%) & & \\
\hline High score $(\geq 12)$ & $6 / 30(20.0 \%)$ & $3 / 30(10.0 \%)$ & & \\
\hline
\end{tabular}

\subsection{Influence of a CL/P on well-being and functioning}

The questionnaires to investigate the influence of a cleft on well-being and functioning were only administered to the participants with a CL/P. Hence, analyses were based on the responses of the 30 patients with a CL/P. Within this group, we investigated whether age or gender significantly influenced well-being and functioning.

The Pearson $\chi 2$ test revealed that the proportion of participants who reported an influence of the CL/P on daily functioning, general well-being, social contacts, family life, applying for a job, work, education and leisure time differed by age (Table 7). Participants from the older age group (i.e., $>50$ years) were more likely to experience a substantial influence of their cleft compared to participants from the younger age groups (i.e., <30 years and 3050 years). 
Table 7

Influence of a CL/P on well-being and functioning per age group

\begin{tabular}{|c|c|c|c|c|c|c|c|c|}
\hline & \multicolumn{6}{|c|}{ Participants with a CL/P $(n=30)$} & \multirow{3}{*}{$\begin{array}{l}\chi^{2} \\
\text { (df) }\end{array}$} & \multirow{3}{*}{$\begin{array}{l}p- \\
\text { value }\end{array}$} \\
\hline & \multicolumn{2}{|l|}{$<30$ years } & \multicolumn{2}{|c|}{$30-50$ years } & \multicolumn{2}{|l|}{$>50$ years } & & \\
\hline & $\begin{array}{l}\text { No } \\
\text { influence } \\
\text { or a little } \\
\text { influence } \\
\text { of the } \\
\text { cleft }\end{array}$ & $\begin{array}{l}\text { A } \\
\text { substantial } \\
\text { influence } \\
\text { of the cleft }\end{array}$ & $\begin{array}{l}\text { No } \\
\text { influence } \\
\text { or a little } \\
\text { influence } \\
\text { of the } \\
\text { cleft }\end{array}$ & $\begin{array}{l}\text { A } \\
\text { substantial } \\
\text { influence } \\
\text { of the cleft }\end{array}$ & $\begin{array}{l}\text { No } \\
\text { influence } \\
\text { or a little } \\
\text { influence } \\
\text { of the } \\
\text { cleft }\end{array}$ & $\begin{array}{l}\text { A } \\
\text { substantial } \\
\text { influence } \\
\text { of the cleft }\end{array}$ & & \\
\hline $\begin{array}{l}\text { Daily } \\
\text { functioning }\end{array}$ & $\begin{array}{l}20 / 21 \\
(95.2 \%)\end{array}$ & $\begin{array}{l}1 / 21 \\
(4.8 \%)\end{array}$ & $\begin{array}{l}5 / 7 \\
(71.4 \%)\end{array}$ & $\begin{array}{l}2 / 7 \\
(28.6 \%)\end{array}$ & $0 / 2(0 \%)$ & $2 / 2(100 \%)$ & $\begin{array}{l}12.86 \\
(2)\end{array}$ & $.004^{\star}$ \\
\hline $\begin{array}{l}\text { General } \\
\text { well-being }\end{array}$ & $\begin{array}{l}20 / 21 \\
(95.2 \%)\end{array}$ & $\begin{array}{l}1 / 21 \\
(4.8 \%)\end{array}$ & $\begin{array}{l}5 / 7 \\
(71.4 \%)\end{array}$ & $\begin{array}{l}2 / 7 \\
(28.6 \%)\end{array}$ & $0 / 2(0 \%)$ & $2 / 2(100 \%)$ & $\begin{array}{l}12.86 \\
(2)\end{array}$ & $.004^{*}$ \\
\hline $\begin{array}{l}\text { Social } \\
\text { contacts }\end{array}$ & $\begin{array}{l}18 / 21 \\
(81.8 \%)\end{array}$ & $\begin{array}{l}3 / 21 \\
(14.3 \%)\end{array}$ & $\begin{array}{l}4 / 7 \\
(57.1 \%)\end{array}$ & $\begin{array}{l}3 / 7 \\
(42.9 \%)\end{array}$ & $0 / 2(0 \%)$ & $2 / 2(100 \%)$ & $\begin{array}{l}8.08 \\
(2)\end{array}$ & $.025^{\star}$ \\
\hline Family life & $\begin{array}{l}21 / 21 \\
(100.0 \%)\end{array}$ & $\begin{array}{l}0 / 21 \\
(0.0 \%)\end{array}$ & $\begin{array}{l}6 / 7 \\
(85.7 \%)\end{array}$ & $\begin{array}{l}1 / 7 \\
(14.3 \%)\end{array}$ & $0 / 2(0 \%)$ & $2 / 2(100 \%)$ & $\begin{array}{l}20.47 \\
(2)\end{array}$ & $.002 *$ \\
\hline $\begin{array}{l}\text { Applying } \\
\text { for a job }\end{array}$ & $\begin{array}{l}19 / 21 \\
(90.5 \%)\end{array}$ & $\begin{array}{l}2 / 21 \\
(9.5 \%)\end{array}$ & $\begin{array}{l}5 / 7 \\
(71.4 \%)\end{array}$ & $\begin{array}{l}2 / 7 \\
(28.6 \%)\end{array}$ & $0 / 2(0 \%)$ & $2 / 2(100 \%)$ & $\begin{array}{l}9.75 \\
(2)\end{array}$ & $.022 *$ \\
\hline Work & $\begin{array}{l}20 / 21 \\
(95.2 \%)\end{array}$ & $\begin{array}{l}1 / 21 \\
(4.8 \%)\end{array}$ & $\begin{array}{l}6 / 7 \\
(85.7 \%)\end{array}$ & $\begin{array}{l}1 / 7 \\
(14.3 \%)\end{array}$ & $0 / 2(0 \%)$ & $2 / 2(100 \%)$ & $\begin{array}{l}14.34 \\
(2)\end{array}$ & $.015^{\star}$ \\
\hline Education & $\begin{array}{l}20 / 21 \\
(95.2 \%)\end{array}$ & $\begin{array}{l}1 / 21 \\
(4.8 \%)\end{array}$ & $\begin{array}{l}4 / 7 \\
(57.1 \%)\end{array}$ & $\begin{array}{l}3 / 7 \\
(42.9 \%)\end{array}$ & $0 / 2(0 \%)$ & $2 / 2(100 \%)$ & $\begin{array}{l}13.3 \\
(2)\end{array}$ & $.002 *$ \\
\hline $\begin{array}{l}\text { Leisure } \\
\text { time }\end{array}$ & $\begin{array}{l}20 / 21 \\
(95.2 \%)\end{array}$ & $\begin{array}{l}1 / 21 \\
(4.8 \%)\end{array}$ & $\begin{array}{l}5 / 7 \\
(71.4 \%)\end{array}$ & $\begin{array}{l}2 / 7 \\
(28.6 \%)\end{array}$ & $0 / 2(0 \%)$ & $2 / 2(100 \%)$ & $\begin{array}{l}12.86 \\
(2)\end{array}$ & $.004^{\star}$ \\
\hline
\end{tabular}

The Pearson $\chi 2$ test also revealed that the proportion of participants reporting an influence of the CL/P on wellbeing and functioning did not differ by gender $(p>.05)$ (Table 8$)$. 
Table 8

Influence of a CL/P on well-being and functioning per gender

\begin{tabular}{|c|c|c|c|c|c|c|}
\hline & \multicolumn{4}{|c|}{ Participants with a CL/P $(n=30)$} & \multirow{3}{*}{$\begin{array}{l}\chi^{2} \\
(\mathrm{df})\end{array}$} & \multirow{3}{*}{$\begin{array}{l}p- \\
\text { value }\end{array}$} \\
\hline & \multicolumn{2}{|l|}{ Male $(n=19)$} & \multicolumn{2}{|l|}{ Female $(n=11)$} & & \\
\hline & $\begin{array}{l}\text { No influence or a } \\
\text { little influence of } \\
\text { the cleft }\end{array}$ & $\begin{array}{l}\text { A substantial } \\
\text { influence of } \\
\text { the cleft }\end{array}$ & $\begin{array}{l}\text { No influence or a } \\
\text { little influence of } \\
\text { the cleft }\end{array}$ & $\begin{array}{l}\text { A substantial } \\
\text { influence of } \\
\text { the cleft }\end{array}$ & & \\
\hline $\begin{array}{l}\text { Daily } \\
\text { functioning }\end{array}$ & $16 / 19(84.2 \%)$ & $3 / 19(15.8 \%)$ & 9/11 (81.8\%) & $2 / 11(18.2 \%)$ & $\begin{array}{l}.029 \\
(1)\end{array}$ & 1.000 \\
\hline $\begin{array}{l}\text { General } \\
\text { well-being }\end{array}$ & $16 / 19(84.2 \%)$ & $3 / 19(15.8 \%)$ & 9/11 (81.8\%) & $2 / 11(18.2 \%)$ & $\begin{array}{l}.029 \\
(1)\end{array}$ & 1.000 \\
\hline $\begin{array}{l}\text { Social } \\
\text { contacts }\end{array}$ & 14/19 (73.7\%) & $5 / 19(26.3 \%)$ & $8 / 11(72.7 \%)$ & $3 / 11(27.3 \%)$ & $\begin{array}{l}.003 \\
(1)\end{array}$ & 1.000 \\
\hline Family life & 18/19 (94.7\%) & $1 / 19(5.3 \%)$ & 9/11 (81.8\%) & $2 / 11(18.2 \%)$ & $\begin{array}{l}1.292 \\
(1)\end{array}$ & .298 \\
\hline $\begin{array}{l}\text { Applying } \\
\text { for a job }\end{array}$ & $15 / 19(78.9 \%)$ & $4 / 19(13.3 \%)$ & $9 / 11(81.8 \%)$ & $2 / 11(18.2 \%)$ & $\begin{array}{l}.036 \\
(1)\end{array}$ & 1.000 \\
\hline Work & $16 / 19(84.2 \%)$ & $3 / 19(15.8 \%)$ & 10/11 (90.9\%) & $1 / 11(9.1 \%)$ & $\begin{array}{l}0.271 \\
(1)\end{array}$ & 1.000 \\
\hline Education & $16 / 19(84.2 \%)$ & $3 / 19(15.8 \%)$ & $8 / 11(72.7 \%)$ & $3 / 11(27.3 \%)$ & $\begin{array}{l}.574 \\
(1)\end{array}$ & .380 \\
\hline $\begin{array}{l}\text { Leisure } \\
\text { time }\end{array}$ & 17/19 (89.5\%) & $2 / 19(10.5 \%)$ & $8 / 11(72.7 \%)$ & $3 / 11(27.3 \%)$ & $\begin{array}{l}1.407 \\
(1)\end{array}$ & .245 \\
\hline
\end{tabular}

\section{Discussion}

The purpose of this study was to investigate the impact of living with a CL/P on esthetics, employment and functioning in Dutch-speaking adolescents and adults with a CL/P. The possible impact of the CL/P was measured using different self-report questionnaires. The responses on these questionnaires were compared with the results of an age- and gender-matched control group consisting of adolescents and adults without a CL/P.

In general, no differences in generic health condition were revealed between participants with and without a CL/P. This finding was in line with the results of Oosterkamp, Dijkstra [10] who found no differences in quality of life (QoL) between participants with a BLCP and an age- and gender-matched control group using the same RAND-36 tool. This finding suggests that adults with a CL/P do not experience a worse health condition compared to individuals without a CL/P. It must be noted that the RAND-36 is a generic, non-categorical QoL instrument. Generic instruments allow for comparisons between individuals with different health conditions and within the whole population [23]. The questionnaire targets several global determinants of QoL, for example physical and social functioning, mental health, vitality and pain. Our findings suggest that the presence of a CL/P does not influence these global QoL determinants. In contrast with generic instruments, condition-specific instruments target elements relevant to a specific medical condition such as a CL/P. Perhaps, patients with a CL/P will demonstrate a 
lower QoL when using condition-specific tools rather than generic questionnaires because latter instruments are much less narrowed to particular problems that these patients might experience. Nevertheless, our findings based on this generic tool are clinically relevant since they suggest that individuals born with a CL/P are not disadvantaged in terms of their general QoL perception compared to individuals without a CL/P. The results in terms of the participants' QoL were in line with the individuals' satisfaction with their lives as a whole (Table 5). The total SWLS score of the participants with a CL/P was rather high, indicating that the respondents were satisfied with general aspects of their lives.

Surprising results were revealed with regard to the influence of a CL/P on appearance and social functioning (Table 4). Participants without a CL/P were significantly less satisfied with the appearance of their jaws compared to participants with a CL/P. Perhaps, individuals with a CL/P have other esthetic standards compared with individuals without a CL/P. It is assumable that adult patients with this congenital condition have adapted their views on appearance and esthetics because they were confronted with problems on these domains during their childhood and adolescence. Previous literature on patient's satisfaction with appearance reported divergent findings. Some studies argued that individuals with a CL/P were less satisfied with particular aspects of their appearance (i.e., upper lip and nose) compared to a control group [10]. Other studies, on the contrary, revealed that most patients with a CL/P were very pleased with their facial appearance [24]. Most likely, methodological differences can account for these varying observations. The study performed by Oosterkamp, Dijkstra [10], for example, only included patients with a BCLP. A BCLP is the most severe manifestation of oral clefts with serious esthetical consequences [25]. Thereby, it might not seem very surprising that the patients with a BCLP included in the study conducted by Oosterkamp et al. (2007) were less satisfied with the appearance of their upper lip.

Despite that the participants with a CL/P in this study were generally satisfied with their appearance, several individuals did report an impact of the cleft on well-being and social functioning (Tables 7 and 8). Especially adults in the older age groups (i.e., participants with an age of 50 years or older) experienced a substantial influence of their cleft on different domains (i.e., daily functioning, general well-being, social contacts, family life, applying for a job, work, education, and leisure time (Table 7)). It seems that the impact of a cleft becomes more apparent when the patient becomes older. This finding was in line with our hypothesis. Nevertheless, this result might also be considered somewhat surprising since one might hypothesize that older patients have learned to cope with the possible influence of their cleft $[26,27]$. To date, few studies paid attention to the experiences of older individuals who were born with a CL/P, which makes a comparison of our findings difficult. One qualitative study investigated older adults' experiences of living with a CL/P [13]. Six adults between the ages of 57 and 82 years were interviewed using semi-structured interviews. The interviews revealed that the CL/P had an ongoing impact on participants' lives, although its relevance shifted over time. Participants described that if the cleft had an impact on their self-confidence as a young adult, it still had a significant influence when they became older. Personal characteristics (such as resilience and self-confidence) are important factors to consider when determining the impact of a cleft on well-being and social functioning. Future studies should take into account these influencing variables. In addition, it should be mentioned that only two participants older than 50 years were included in the present study (Table 7). Perhaps, particular individual characteristics of these individuals might have accounted for the obtained results. Further research, which includes more individuals in the older age groups, is necessary in order to make more valid conclusions.

Interestingly, the findings in terms of well-being and social functioning seemed to be in line with the participant's results on the Social Avoidance and Distress Scale (SADS). Despite that the participants with a CL/P did not 
experience significantly more social anxiety or did not show more avoidance behavior compared to participants without a CL/P, $86.7 \%$ of the participants with a CL/P had an average or high SADS score which suggests that respondents did experience an influence of their cleft on social activities (Table 7). A study performed by Berk, Cooper [28] investigated social anxiety in adults with a CL/P aged 18 to 69 years. Responses of the participants on the SADS were compared with responses from their adult siblings without a CL/P. Findings revealed that the participants with a CL/P reported significantly more social anxiety than their siblings. In addition, participants with a CL/P were found to experience lower self-esteem and social support.

This study was one of the first to determine the long-term impact of living with a CL/P on esthetics, employment and social functioning. In general, the findings of our study revealed no differences between adolescents and adults with and without a CL/P with regard to most of these aspects (i.e., education, employment, quality of life, and social functioning). Considering age within the group of participants with a $\mathrm{CL} / \mathrm{P}$, however, the results demonstrated that older individuals were more likely to experience an impact of their cleft on well-being and social functioning. The findings of this study are directly relevant to clinical practice. Patients with a CL/P are usually discharged from the cleft team service when they are between 16 and 20 years old [29]. Based on our findings, one might argue that older patients might still (or again) feel the need to receive support in dealing with the social and emotional aspects of a CL/P. Cleft teams should consider to recall these older patients in order to provide adequate socio-emotional support whenever needed. These patients might perhaps benefit from peer contacts, for example initiatives like support groups. The specific effects of such peer contacts on well-being and social functioning remains a topic for further research. Despite the relevance of this study, there are some limitations that should be discussed. Possibly, sampling bias occurred when recruiting participants for this study. It could be that only those individuals, who experienced no influence of their cleft on daily living, agreed to take part in this study. "Well-being" might have been a delicate subject for patients who actually experienced issues in this domain. These sensitive topics can, in turn, raise the problem of social desirability bias [30]. If participants with a CL/P tended to answer questions in a manner that will be viewed as favorable by others, it might be the case that our findings are an underestimation of the actual impact of a CL/P. Qualitative research might be an answer to this problem by providing in-depth information and insights on the patients' well-being starting from an emic perspective (i.e., the perceptions, feelings, and experiences of the participants themselves) [31, 32]. Future qualitative studies should respond to the limitations of previous qualitative studies by taking into account factors such as age. Beside the issue of social desirability bias, it might also be possible that participants would have provided other answers if they would have completed the questionnaire at a different moment or time. Longitudinal research on this topic is therefore urgently needed to determine possible fluctuations in time with regard to the impact of living with a CL/P.

\section{Conclusions}

The purpose of this study was to investigate the impact of living with a CL/P on esthetics, employment, and general social functioning in Dutch-speaking adolescents and adults with a CL/P. The possible impact of the CL/P was measured using different self-report questionnaires. The responses on these questionnaires were compared with the results of an age and gender matched control group consisting of adolescents and adults without a CL/P. In general, the findings of our study revealed no significant differences between adults with and without a CL/P with regard to employment and social functioning. With regard to esthetics, the findings revealed that participants without a CL/P were less satisfied with the appearance of their jaws compared to participants with a CL/P. Considering age within the group of participants with a CL/P, however, the results demonstrated that older individuals were more likely to experience a negative impact of their cleft on well-being and social functioning. The 
findings of this study suggest that older individuals with a CL/P might benefit from additional socio-emotional support, for example peer contacts and support groups. Longitudinal research on this topic is highly needed to determine possible fluctuations in the impact of living with a CL/P.

\section{Declarations}

Ethical Approval and Consent to participate: this study was approved by the Ethics Committee of the (blinded for review) University Hospital. Every individual participated voluntarily and signed an informed consent.

Consent for publication: every author gave consent for publication.

Availability of supporting data: The datasets used and/or analyzed during the current study are available

from the corresponding author on reasonable request

Competing interests: There is no conflict of interest.

Funding: This work was supported by the Research Fund Flanders under Grant 1120919N (Grant for the first author).

Authors' contributions: CA designed and conceptualized the study, conducted the statistical analysis and interpreted the results, and drafted the manuscript. ED, KB, NV, MC, DS, GW coordinated the data collections (data acquisition) and provided feedback on the paper. KVL designed and conceptualized the study, coordinated the data collections (data acquisition) and provided feedback on the paper. All authors have read and approved the final manuscript.

Acknowledgements: not applicable.

\section{References}

1. Stock, N.M., K.B. Feragen, and N. Rumsey, "It Doesn't All Just Stop at 18": Psychological Adjustment and Support Needs of Adults Born with Cleft Lip and/or Palate. The Cleft Palate-Craniofacial Journal, 2015. 52(5): p. 543-554.

2. Gaggl, A., G. Schultes, and H. Kärcher, Aesthetic and Functional Outcome of Surgical and Orthodontic Correction of Bilateral Clefts of Lip, Palate, and Alveolus. The Cleft Palate-Craniofacial Journal, 1999. 36(5): p. 407-412.

3. Gaggl, A., et al., Cephalometric and Occlusal outcome in Adults with Unilateral Cleft Lip, Palate, and Alveolus after Two Different Surgical Techniques. The Cleft Palate-Craniofacial Journal, 2003. 40(3): p. $249-255$.

4. Sinko, K., et al., Evaluation of Esthetic, Functional, and Quality-of-Life Outcome in Adult Cleft Lip and Palate Patients. The Cleft Palate-Craniofacial Journal, 2005. 42(4): p. 355-361.

5. Harris, D. and A. Carr, Prevalence of concern about physical appearance in the general population. British journal of plastic surgery, 2001. 54(3): p. 223-226.

6. Kapp, K.J.T.C.p.j., Self concept of the cleft lip and or palate child. 1979. 16(2): p. 171-176.

7. Feragen, K.B., et al., Adolescents with and without a facial difference: The role of friendships and social acceptance in perceptions of appearance and emotional resilience. Body Image, 2010. 7(4): p. 271-279. 
8. Pope, A.W. and J. Ward, Self-Perceived Facial Appearance and Psychosocial Adjustment in Preadolescents with Craniofacial Anomalies. The Cleft Palate-Craniofacial Journal, 1997. 34(5): p. 396-401.

9. Hunt, O., et al., The psychosocial effects of cleft lip and palate: a systematic review. European journal of orthodontics, 2005. 27(3): p. 274-285.

10. Oosterkamp, B.C.M., et al., Satisfaction with treatment outcome in bilateral cleft lip and palate patients. International Journal of Oral and Maxillofacial Surgery, 2007. 36(10): p. 890-895.

11. Persson, M., M. Becker, and H. Svensson, Academic achievement in individuals with cleft: a population-based register study. The Cleft palate-craniofacial journal, 2012. 49(2): p. 153-159.

12. Danino, A., et al. Social adjustment in French adults from who had undergone standardised treatment of complete unilateral cleft lip and palate. in Annales de chirurgie plastique et esthetique. 2004.

13. Hamlet, C. and D. Harcourt, Older adults' experiences of living with cleft lip and palate: a qualitative study exploring aging and appearance. The Cleft palate-craniofacial journal : official publication of the American Cleft Palate-Craniofacial Association, 2015. 52(2): p. e32-40.

14. Van der Zee, K. and R. Sanderman, RAND-36. Groningen: Northern Centre for Health Care Research, University of Groningen, the Netherlands, 1993. 28(6).

15. Aaronson, N.K., et al., Translation, validation, and norming of the Dutch language version of the SF-36 Health Survey in community and chronic disease populations. Journal of clinical epidemiology, 1998. 51(11): p. 1055-1068.

16. Diener, E., et al., The satisfaction with life scale. Journal of personality assessment, 1985. 49(1): p. 71-75.

17. Pavot, W., et al., Further validation of the Satisfaction with Life Scale: Evidence for the cross-method convergence of well-being measures. Journal of personality assessment, 1991. 57(1): p. 149-161.

18. Arrindell, W.A., J. Heesink, and J.A. Feij, The satisfaction with life scale (SWLS): Appraisal with 1700 healthy young adults in The Netherlands. Personality individual differences, 1999. 26(5): p. 815-826.

19. Watson, D. and R. Friend, Measurement of socio-evaluation anxiety. J Consult Clin Psychol, 1969. 33: p. 448457.

20. Tennison, C., The repair of the unilateral cleft lip by the stencil method. J Plastic reconstructive surgery, 1952. 9(2): p. 115-120.

21. Millard, D., Rotation-advancement principle in cleft lip closure. Cleft Palate J, 1964. 12: p. 246-252.

22. Sommerlad, B., A technique for cleft palate repair. Plastic reconstructive surgery, 2003. 112(6): p. $1542-1548$.

23. Matza, L.S., et al., Assessment of health-related quality of life in children: a review of conceptual, methodological, and regulatory issues. Kline \%J Value in health, 2004. 7(1): p. 79-92.

24. Strauss, R.P., H. Broder, and R.W. Helms, Perceptions of appearance and speech by adolescent patients with cleft lip and palate and by their parents. The Cleft palate journal, 1988. 25(4): p. 335-42.

25. Shaw, W., Global strategies to reduce the health care burden of craniofacial anomalies: report of WHO meetings on international collaborative research on craniofacial anomalies. The Cleft palate-craniofacial journal, 2004. 41(3): p. 238-243.

26. Thompson, A. and L. Broom, Positively managing intrusive reactions to disfigurement: an interpretative phenomenological analysis of naturalistic coping. Diversity in Health Care, 2009. 6(3): p. 171-180.

27. Mani, M., M. Carlsson, and A. Marcusson, Quality of life varies with gender and age among adults treated for unilateral cleft lip and palate. The Cleft palate-craniofacial journal, 2010. 47(5): p. 491-498. 
28. Berk, N.W., et al., Social anxiety in Chinese adults with oral-facial clefts. The Cleft palate-craniofacial journal : official publication of the American Cleft Palate-Craniofacial Association, 2001. 38(2): p. 126-33.

29. CLAPA, C.L.P.A. Timeline of cleft interventions. 2019; Available from: https://www.clapa.com/treatment/timeline/\#21years.

30. Krumpal, I., Determinants of social desirability bias in sensitive surveys: a literature review. Quality Quantity, 2013. 47(4): p. 2025-2047.

31. Sutton, J. and Z. Austin, Qualitative Research: Data Collection, Analysis, and Management. The Canadian journal of hospital pharmacy, 2015. 68(3): p. 226-31.

32. Harris, M., History and significance of the emic/etic distinction. \%J Annual review of anthropology, 1976. 5(1): p. 329-350. 